\title{
On the Relationship between Writing Motivation, Academic Achievement, and Gender in tertiary education
}

\section{Meriem Ouahidi}

Faculty of Arts and Human Sciences, Sultan Moulay Slimane University, Beni Mellal, Morocco

\begin{abstract}
The present paper seeks to investigate the students' writing motivation and its relationship with two dependent variables: gender and writing academic performance. To achieve this aim, a ten-item Likert scale questionnaire was designed and administered to 98 undergraduate students, randomly selected from the English Department at Sultan Moulay Slimane University, Beni Mellal. To compute the data, three tests were conducted, ANOVA, Pearson and T-test. The statistical analysis demonstrated that extrinsic motivation is the most frequent writing orientation and that both motivation constructs, intrinsic and extrinsic, positively correlate with the students' writing performance in semesters three and four writing exams. Additionally, the study also showed a significant difference between males and females about their motivational orientation.
\end{abstract}

Keywords - academic achievement, extrinsic motivation, gender, intrinsic motivation, orientation goal.

\section{INTRODUCTION}

Writing is recognized as a necessary skill for academic success at all levels; students are required to write clearly, accurately, and fluently. Otherwise, their writing ability will negatively affect their academic performance. Writing is considered a complex task that requires balancing content, grammar, organization, mechanics, choice of the vocabulary and spelling. The multiplicity of challenges that novice writers should overcome to write a coherent, unified and organized piece of writing entails that the learners should be highly motivated. In a task as complicated as writing, motivation becomes a top priority in writing accomplishment.

Motivation, Gardner (1985) assumes, refers to the desire, effort and positive attitude towards learning that entices the learners to achieve their goals. In the same line, Brown (1987, p.114) defines it as "an inner drive, impulse, emotion or desire that moves one to a particular action". It is generally believed that motivation is a key component for successful academic proficiency; it plays a pivotal role in promoting language learning in academia. Motivation, according to Gardner (1985), involves four interrelated elements: the goal, the desire and the positive attitude to reach the goal, and the effort invested to achieve the goal.
As a complex cognitive process (Flower \& Hayes, 1981),writing reflects the learners' development and improvement in language learning. Therefore, there is a general agreement among the English Department teachers at Sultan Moulay Slimane that students should strive to write properly, and regularly in different genres to succeed in their exams. It is commonly held among English language teachers that their students are reluctant to invest time and effort to improve their writing skill and make it meet the requirements of acceptable writing standards.

In Moroccan higher education, writing plays a leading role in the successful development of students. Aware of its vital role, the English departments bestow on the writing skill a huge significance. In fact, writing is taught in four successive semesters where students are initiated to sentence structure through the focus on the mechanics of language use. Then semester two students are introduced to constructing well-organized paragraphs. In semester three, there is a shift of focus from the paragraph to the essay. The last semester teachers emphasize the organization and process of writing a research paper. Throughout the four semesters, these courses aim to familiarize the student with writing techniques, process, and organization. Teachers seek to develop students' writing ability so that they can transcend their weaknesses and improve their writing faculty. 
Second, final exams in most courses are written. Therefore, the evaluation of the students' answers relies much on the quality of the students' writing skill. Third, lectures are delivered during the teaching process which entails students' need to take notes, summarize information, and synthesize to develop the lessons. Hence, writing is critical not only to succeed in exams but also to guarantee continuity. Moreover, to access graduate studies, students must succeed in the written entrance exam. As a result, students' academic proficiency relies to a great extent on the students' writing competence at the graduate and undergraduate levels. A student, with good writing ability, will necessarily face very few problems to succeed at the university level and vice versa. Besides, good writing skills are deemed necessary in the job market.

A plethora of research delved into the students' writing ability at different levels, options and academic settings. However, few of them evaluated the relationship between the constructs of motivation (intrinsic and extrinsic), successful academic achievement and gender. Research in this complex issue is very scanty. To my knowledge, no study, in the Moroccan context, has taken into account the interrelationship between these three variables. Accordingly, there is an urgent need to cast light on this new area of research in the Moroccan Higher education context.

\section{REVIEW OF THE LITERATURE}

\subsection{MOTIVATION AND LANGUAGE LEARNING}

It is widely believed that motivationis a crucial factor that triggers learners' perseverance, interest and development of skills in language learning, i.e. there is a permanent correspondence between motivation and academic proficiency. That is why Dornyei (2000) argues thatlearners' achievement of short- and long-term goals relies on motivation which provides them with the driving force to instigate and keep up an interest in learning. In fact, without sufficient motivation, adequate teaching material, curricula, and qualified teachers cannot guarantee students' positive academic achievement.Unless they are highly motivated to attain their academic goals, students will not be able to overcome their learning problems that hinder the improvement of their scholarly performance.

In language learning, Oxford and Shearin (1994) maintain that motivation affects the type and amount of input students get in the target language, the learning strategies they apply and the cognitive processes they adopt. In the same vein, previous research (Pintrinch\& Schunk, 2002; Fazel \& Ahmadi, 2011) maintains that motivation enhances energy and effort, guides language learners to achieve their goals, and encourages them to start an activity and persist in doing it.

\subsection{INTRINSIC AND EXTRINSIC MOTIVATION AND LANGUAGE LEARNING.}

In their self-determination theory, Deci and Ryan (2000) distinguish between two types of motivational goals: intrinsic and extrinsic motivation, based on the individual's source of motivation. While the former involves undertaking an activity for its inherent benefits, the latter is the result of internal factors and motivators. Likewise, Deci and Ryan (1985) postulate that intrinsic motivation boosts learners' internal satisfaction, autonomy, volition, and competence; whereas, extrinsic motivation presupposes the expectation of a reward or the avoidance of punishment.

Intrinsic motivation appeals to the learners' internal satisfaction; it is an inherent natural inclination to perform a task. In this respect, learners will not need an incentive to get engaged in an activity. They will persevere to get it accomplished because of the contentment and gratification it will bring about.Extrinsic motivation, on the other hand, refers to the satisfaction that learners get due to external factors such as rewards, or punishment from parents, a system, institution and so on (Brown, 1987). Rewards can be in the form of positive feedback, money, prizes, and/or good grades. Punishment can be characterized in negative feedback and physical, verbal, and/ or moral punishment.

\subsection{MOTIVATION AND ACADEMIC ACHIEVEMENT}

Previous comparative research about the two constructs of motivation show that intrinsic motivation is more correlated with better academic proficiency than extrinsic motivation. Afzal et al (2010) assert, in a study conducted on 324 Pakistan higher education students, that intrinsically and extrinsically motivated students have a positive academic performance.

Learners with intrinsic motivation are likely to learn for the sake of learning that is why they tend to attain better academic results than learners with extrinsic motivation who experience some external pressure to invest effort in learning (Pintrinch\& Schunk, 2002; Ryan \& Deci, 2000; Vallerand, 1997; Wu, 2003). Additionally, Brown (1987) contends that external motivation undermines overtime the learners' disposition to invest time and effort in learning once the motivator is removed, which can affect the learners' motivation negatively. In the same vein, ascribing positive academic achievement to external factors (rewards or punishment) may result in low efficacy beliefs in one's ability to fulfill arduous tasks and attain ones' goals. This is due to the correlation between self-efficacy and intrinsic motivation rather than extrinsic one (Zimmerman, 2000). 


\subsection{MOTIVATION AND WRITING}

Without constant practice, regular reading, and permanent patience, the student's improvement in their writing capacity turns out to be difficult to reach;all three require an infallible motivation. Flower and Hayes, (1981)point out that writing involves the orchestration of different complex cognitive processes: memory retrieval, goal setting, planning, problem-solving, and evaluation. The complexity of these processes reflects how much motivation the students need to achieve their writing goals.

Few studies address the issue of motivation and learners' writing performance. One of these studies was conducted by Fazel and Ahmadi (2011) on 245 IELTS Iranian students. It concluded that motivation positively impacts their writing, but they found no significant difference between the students' integrative and instrumental motivation and their academic performance. Along similar lines, Another study on 100 EFL Iranian medical students from Shiraz University, Nourinezhad et al. (2017) found out that motivation is a top priority in writing and intrinsically oriented students are moresuccessful than extrinsically oriented ones.

\subsection{MOTIVATION AND GENDER}

There is a general consensus among researchers that males and females do not differ in general cognitive abilities. However, it is commonly believed that specific abilities vary between males and females.

According toPajares (2003, p 157), "Language arts in school is typically associated with a feminine orientation in part because writing is viewed by most students, particularly younger students, as being a female-domain. As a consequence, a feminine orientation is associated with motivational beliefs related to success in writing."Similarly, in their study on elementary and middle school boys and girls, PajaresandValiante, (2001) found out that girls and boys have a similar writing performance but girls have a better writing self- efficacy. However, Meece et al. (2006) concluded that females are more motivated than males in reading and writing skill. This discrepancy between males and females remains strongly marked throughout their schooling years.Males, on the other hand, are more motivated in mathematics and sports. Each gender, according to this study is associated with sextyped areas.Congruent findings were reported by several researchers as Reilly et al. (2019 p. 452)who asserted, "Researchers have reported gender gaps in writing in favor of females across different populations and designs." By the same token, Omari et al. (2018) conducted a study on a sample population of 329 students from three Moroccan universities and found out that females are more motivated to study English than males. Additionally, Meece et al. (2006) asserted that in general females are more motivated to read and write about feminine based topics; whereas, boys prefer writing about such topics as sports, mathematics and science.

Reilly et al. (2019) admitted the need for more research on writing to find out gender differences moderated by the two constructs of motivation. It is very important to mention that a very limited number of studies has explored the issues of gender differences in writing as Pajares (2003) and Reilly et al. (2019) mentioned.

\subsection{RESEARCH QUESTIONS AND HYPOTHESES}

In the light of the literature review, the fundamental aim of the present study is two-fold: 1) to examine the relationship between the two constructs of motivation and academic achievement and 2) to explore the correlation between gender and writing motivation. This paper is, therefore, an attempt to answer the following research questions:

1- Are students intrinsically or extrinsically motivated to write?

2- Is there any correlation between intrinsic and extrinsic motivation and writing academic achievement?

3- Are there any gender differences on intrinsic and extrinsic writing motivation?

4- Are there any gender differences on academic achievement?

Consistent with previous research, we hypothesize that

1- Moroccan higher education students are extrinsically motivated.

2- There is a correlation between their motivation construct and academic achievement.

3- Females are more intrinsically motivated than males.

4- Females' academic achievement is better than that of males.

\subsection{PARTICIPANTS}

\section{METHODOLOGY}

The sample population of the present study consists of 98 semester five undergraduate students who studied composition and writing techniques during four successive semesters. All the participants are enrolled in the English department at Sultan Moulay Slimane University. The male-female ratio is approximately the same since the sample consisted of 43 males and 45 females. The study takes into account only students whose ages ranged between 19 and 25 so that the age variable will not affect the findings. By the time of the study, all the participants have studied English as a foreign language for at least 5 
years, andthey speak Moroccan Arabic or Amazigh as their native language.

\subsection{INSTRUMENT}

To measure the participants' motivational orientation (intrinsic or extrinsic), one main instrument was employed in the study, mainly the questionnaire. It consists of three main parts: the first part is devoted to the demographic information of the participants: age, gender, and number of years of studying English. The second part includes two items about the grades the students got during semesters three and four composition final exams. The mean of the two grades will be employed to compute their academic achievement. It is important to mention that the students are requested to write a five-paragraph essay, and their writings are evaluated by their teachers who take into account both form and content.

In the third part, the respondents were asked to respond to ten items in total on a five-point Likert scale $(5=$ strongly agree, 4= agree, 3= somewhat agree, 2 disagree, 1= strongly disagree). Six items were allocated for intrinsic and four for extrinsic motivation. These items were inspired by Pulford et al. (2018).

In a pilot study, the questionnaire was first administered to fifteen students from the English Department. After making some minor modifications, the questionnaire became clear and amenable within a reasonable time limit. The consistency obtained from the Cronbach alpha value of the questions that target intrinsic motivation exhibited a moderately high Coefficient (.71). Equally reliable are the questions that address extrinsic motivation which yielded a consistency value of (.67).

\subsection{DATA ANALYSIS PROCEDURES}

To answer the research questions, Statistical Package for the Social Sciences program (SPSS), version 24.00, was used to analyze the compiled data through descriptive and inferential statistics. The descriptive analysis was carried out toelicit the mean scores and standard deviation to measurethe students' motivational orientation. The inferential statistics conducted to pinpoint the correlation between three variables under investigation (motivation constructs, gender, academic achievement) were the ANOVA, Pearson and Independent sample t-test. These Correlation tests are meant to attain the research objectives in terms of analysis and interpretation of the data obtained.

\section{ANALYSIS}

The locus of this study is to elicit the interrelationship between three variables: gender, academic performance and motivational goal orientations, intrinsic and extrinsic and to answer the research questions. That is why three different tests were conducted and reported in the tables below.

\subsection{MOTIVATION AND ACADEMIC ACHIEVEMENT}

The participants are classified with regard to the two variables under investigation, namely writing academic performance and writing motivational constructs. To answer the first research question about whether the participants are intrinsically or extrinsically motivated, the means and standards of deviation were computed for the orientation goals and students' grades and reported in table 1 .

Table 1: Descriptive statistics for motivation and academic achievement

\begin{tabular}{|l|l|l|l|l|}
\hline \multicolumn{2}{|l|}{} & Academic Achievement & Intrinsic_Motivation & Extrinsic_motivation \\
\hline \multirow{N}{*}{} & Valid & 88 & 88 & 88 \\
\cline { 2 - 5 } & Missing & 0 & 0 & 0 \\
\hline Mean & 8.5455 & 3.0318 & 2.2714 \\
\hline Std. Deviation & 2.27888 & .95889 & .77169 \\
\hline
\end{tabular}

The descriptive statistics in table 1 illustratethe rank ordering of the motivation constructs. The comparison reveals that the mean score of extrinsic motivation (2.27) ranked better than that of the intrinsic one (3.03) on a 1 to5 scale. The lower mean of extrinsic motivation indicates that the majority of students are more extrinsically motivated. The means of the students' motivational orientation indicate that the participants of this study write to succeed, get good grades, and find a good job.
Accordingly, this finding reflects the homogeneity between the two motivational constructs.

It is also obvious that the mean score of students' academic performance is low (8.54) since the majority get less than the average grade (10/20), which reflects the students' poor command of the writing skill. In addition, the standard deviation values are not widely spread since the obtained measures are not far from the means. 
Running the one-way analysis of variance (ANOVA test)to disclose if there is significant difference between students' final exam writing grades and the intrinsic construct of motivation. The statistics in table 2 reveal that there is a significant difference between the two cohorts since the $\mathrm{p}$ value is smaller than 0.05 ,i.e. intrinsically and extrinsically motivated students differ with regards to their academic performance in writing.

Table 2: The ANOVA test between motivation constructs and writing proficiency

\begin{tabular}{|lllll|}
\hline Academic Achievement & \multicolumn{5}{l|}{} \\
\hline Intrinsic & $\mathrm{df}$ & Mean Square & $\mathrm{F}$ & Sig. \\
Between Groups & 31 & 11.426 & 6.556 & .001 \\
Within Groups & 56 & 1.743 & & \\
\hline Extrinsic & & & 4.099 & .000 \\
Between Groups & 17 & 13.258 & & \\
Within Groups & 70 & 3.235 & & \\
& & & & \\
\hline
\end{tabular}

To adequately interpret the significance of the Pearson correlation analysis between the motivational orientation of the respondents and their academic achievement, Morgan, Leech, Gloeckner, \& Barrett, (2004) criteria were adopted: .30 (little relationship), .30 to .49 (moderate relationship), .50 to .69 (strong relationship), and .70 and above (very strong relationship).

The Pearson correlation analysis demonstrates that there is a meaningful relationship between the scores the students get in the final exam and intrinsic motivation because of the computed significance 0.00 ( $p<005)$, which is statistically meaningful. Therefore, the null hypothesis was rejected. There is a positive significant correlation between intrinsic motivation and academic achievement. This positive correlation between these two variables is also statistically significant since coefficient .845 reveals a very strong relationship between the students' scores and their goal orientation.

Table 3: Pearson correlation coefficient between intrinsic motivation and writing proficiency

\begin{tabular}{|l|l|l|l|}
\hline \multicolumn{2}{|l|}{} & Academic Achievement & IntrinsicMotivation \\
\hline Academic Achievement & Pearson Correlation & 1 & $.845^{* *}$ \\
\cline { 2 - 4 } & Sig. (2-tailed) & & .000 \\
\cline { 2 - 4 } & $\mathrm{N}$ & 88 & 88 \\
\hline
\end{tabular}

Table 4 presents that the significance value 0.000 is lower than $0.005(\mathrm{p}<0.005)$. Consequently, there isalso a strong correlation between the students' extrinsic goal orientation and their writing performance since the coefficient.61 occurs between .50 and .69 . This provides enough evidence that the students' motivational orientations affect their writing ability. Apparently,a concrete correspondenceholds between students' intrinsic and extrinsic goal orientation andtheir writing performance. More important, students with intrinsic motivation get higher grades than students with extrinsic motivation.

Table 4: Pearson correlation coefficient between extrinsic motivation and writing proficiency

\begin{tabular}{|l|l|l|l|}
\hline & Academic Achievement & Extrinsic_motivation1 \\
\hline Academic Achievement & Pearson Correlation & 1 & .612 \\
\hline
\end{tabular}




\begin{tabular}{|l|l|l|l|}
\hline Sig. (2-tailed) & & .000 \\
\hline $\mathbf{N}$ & 88 & 88 \\
\hline
\end{tabular}

\subsection{MOTIVATION AND GENDER}

An independent sample t-test was run to examine the total scores of males and females about the constructs of motivation: intrinsic and extrinsic.

Table 5: T-test for the constructs of motivation Academic Achievement and gender

\begin{tabular}{|l|l|r|r|r|r|}
\hline & Gender & \multicolumn{1}{|c|}{$\mathrm{N}$} & \multicolumn{1}{c|}{ Mean } & Std. Deviation & Std. Error Mean \\
\hline Intrinsic_Motivation & male & 43 & 3.4633 & .81730 & .12464 \\
\cline { 2 - 6 } & Female & 45 & 2.6195 & .90805 & .13536 \\
\hline Extrinsic_motivation & male & 43 & 1.9151 & .54142 & .08257 \\
\cline { 2 - 6 } & Female & 45 & 2.6118 & .80940 & .12066 \\
\hline Academic Achievement & male & 43 & 7.3963 & 1.78898 & .27282 \\
\cline { 2 - 6 } & Female & 45 & 9.7011 & 1.81937 & .27122 \\
\hline
\end{tabular}

Table 5 shows the relationship between gender and motivational orientations. The results of descriptive statistics indicate that females are slightly more intrinsically motivated to write than males as the mean results demonstrate. The mean score of females (2.6195) is lower than that of males (3.4633). As for extrinsic motivation, it seems that males are more extrinsically motivated than females. These findings support the third hypothesis for they clearly favor females. Therefore, Moroccan female students enjoy writing activities and find them satisfactory more than males. Although the means of both males (7.39) and females (9.70) do not reach the average (10/20) which guarantees success, females get better grades than males. This result conforms with the results of the correlation between gender and goal orientations and therefore confirm hypothesis three and four.

\section{DISCUSSION AND RECOMMENDATIONS}

The data analysis comes up with several revealing findings. The statistics of the present study imply that motivation is significantly correlated with the participants' academic performance in writing and with gender. These findings are tosome extent consistent with previous research.

First, the descriptive analysis of the students' motivational orientations reveals that extrinsic motivation is highly manifest in Moroccan students, as the tabulated statistics display. Therefore, the participants of this study do not write for personal satisfaction, but they write more for success, grades, etc. Such external motivators seem to be the stimulus for students' motivation. This finding is
The results of this test are visualized in the following table: consistent withDeci and Ryan (2000) claim that,usually, teachers are unsatisfied with students' focus on extrinsic goals.

Second, the results suggest that there is a significant correlation between the participants' writing ability and their writing intrinsic motivation. Students with higher intrinsic motivation get better grades than students with lower intrinsic motivation, i.e. students who enjoy writing and express self-satisfaction are likely to attain their goal: academic accomplishment. In the literature, it is commonly believed that intrinsic motivation has an educational advantage over extrinsic motivation.

Third, there is also a strong correlation between the extrinsic construct of motivation and academic achievement. However, it can be reported that students with extrinsic motivation do not get grades as high as those of the students with intrinsic motivation. Therefore, learners who inherently value writing are likely to achieve higher grades. However, the descriptive statistics visualized in table 1 show that the number of students with intrinsic motivation is limited (3.03). This finding complies with the mean $(8,54)$ of students' writing scores in the final exam. This conveys that when the intrinsic and/or extrinsic motivation of the learner is high, the writing academic grade increases.

The result of this study conforms with the study by Yuangbing (2011). He found that the learners' motivation in writing impacts their writing scores in second language learning. This view is also consolidated by Afzah et al. (2010, p. 84) who admitted that there is a "positive and mutually causal relationship between student's motivation and student's academic performance. This relationship is 
reciprocal, meaning students who are more motivated perform better, and students who perform better become more motivated". Interestingly, intrinsic motivation promotes learners writing performance much better than extrinsic motivation. Extrinsic motivation cannot last for a long time since it is associated with a reward. Once the reward disappears, the motivation disappears too (Brown, 1987). Intrinsic motivation, on the other hand, amplifies students' performance because it is imbued by the learners' interest in the subject matter, writing. Importantly, both cohorts get means below the average which highly reflects their academic grades in writing.

Finally, the results of the t-test run to investigate the relationship between gender and motivation show that females are more intrinsically motivated than males and, therefore, get better writing scores than males. This unsurprising finding, which corroborates hypotheses three and four, is consistent with Meece et al.(2006) and Pajares and Valiante, (2001) who contended that the humanities is a field where females surpass males. Writing seems to be a stereotyped feminine skill. This gender difference may be attributed to the frequent practice of girls to writing. Unlike males, females seem to invest more effort and time in writing. This statement is further confirmed by the means of academic achievement of males and females.

Because motivation is not stable, and it changes over time, the EFL teachers should do their best to motivate their students through the use of timely positive and accurate feedback. The writing tasks should be varied and challenging to meet the needs of different learners. Last but not least, teachers should create writing opportunities that are likely to boost students' effort and time they devote to writing.

\section{CONCLUSION}

This study has investigated the relationship between three main variables namely intrinsic and extrinsic motivation, academic achievement and gender. To carry out the study, a questionnaire was designed and administered to tertiary students belonging to the English Department at Sultan Moulay Slimane University. The statistics clearly display that extrinsic motivation is frequent among the participants and that there a significant correlation between the extrinsic and intrinsic motivational constructs and students' writing performance. Gender also seems to correlate with motivation, favoring females who are more intrinsically motivated than males. Although this study is very informative, more future research is required to understand better the students' poor performance in academic writing in higher education.
The main limitation of the present study lies in its focus on quantitative data. Although very informative in nature, the study may have yielded different findings if the researcher has taken into account a different method of data collection: interviews and focus group discussions for instance. The aim is to allow students to explain their responses and maybe allow for more understanding of the issue of motivation in higher education. In addition, the sample population was limited to one main level (semester five students) and one specific context (English department students). Other levels, other contexts and other skills (reading, speaking, listening) should be dealt with in future research, to discover the different factors that affect the students' performance in EFL contexts.

\section{REFERENCES}

[1] Afzal, H., Imran, A., Khan, M. A., \& Hamid, K. (2010). A Study of University Students' Motivation and Its Relationship with Their Academic Performance. International Journal of Business and Management, 13 (8), 80-88

[2] Brown. H.D. (1987). Principles of language learning and teaching (2nd ed.). Englewood Cliffs, NJ: Prentice-Hall.

[3] Deci, E. L., \& Ryan, R. M. (1985). Intrinsic motivation and self-determination in human behavior. New York: Plenum Press.

[4] Deci, E.L. \& Ryan, R.M.(2000). Intrinsic and extrinsic motivations: Classic definitions and new directions. Contemporary Educational Psychology, 25(1), 54-67.

[5] Dornyei, Z. (2000). Motivation in second and foreign language learning. Language Teaching, 31, 117-135.

[6] Fazel, I., \& Ahmadi, A. (2011). On the relationship between writing proficiency and instrumental/integrative motivation among Iranian IELTS candidates. Theory and Practice I Language Studies, 1(7),747-757.

[7] Flower, L.S., \& Hayes, J.R. (1981). A cognitive process theory of writing. College Composition and Communication, 32, 365-387.

[8] Gardner, R. C. (1985). Social psychology and second language learning: The role of attitudeand motivation. London: Edward Arnold.

[9] Meece, J., Glienke, B., \& Burg, S. (2006). Gender, and motivation. Journal of School Psychology, 44, 351-373. Doi:10.1016/j.jsp.2006.04.004.

[10] Morgan, G.A. Leech, N.L. Gloeckner, G.W., Barrett, K.C. (2004). SPSS for Introductory Statistics: Use and Interpretation. Lawrence Erlbaum Associates Publisher

[11] Nourinezhad, S., Shokrpour, N., and Shahsavar, Z., (2017). The Relationship between Intrinsic/Extrinsic Motivation and Medical Students' L2 Writing. Khazar Journal of Humanities and Social Sciences20 (4) 71-81.

[12] Omari, O, Moubtassime, M., \&, Ridouani, D. (2018). Assessing Moroccan University Students' English Learning 
Motivation: A Comparative Study. Advances in Language and Literary Studies. 9(1):81-88.

[13] Oxford, R., \&Shearin, J. (1994). Language learning motivation: Expanding the theoretical framework. Modern Language Journal, 78(1), 12-28.

[14] Pajares, F., \&Valiante, G. (2001). Gender differences in writing motivation and achievement of middle school students: A function of gender orientation? Contemporary Educational Psychology, 26(3), 366-381.

[15] Pajares, F. (2003) self-efficacy beliefs, motivation, and achievement in writing: a review of the literature. Reading \& Writing Quarterly, 19: 1397158, 2003

[16] Pintrich, P. R., \& Schunk, D. H. (2002). Motivation in education: Theory, research, and applications (2nded.). Englewood Cliffs, NJ: Prentice-Hall.

[17] Pulford, S., Tan, J., jsepiModell, A., Gonzalez, M.R. (2018). Satisfaction: Intrinsic and Extrinsic Motivation in Engineering Writing Course- work. Proceedings of the ASEE Annual Conference. 23- 43.

[18] Reilly, D., Neumann, D.L. \& Andrews, G. (2019). Gender Differences in Reading and Writing Achievement: Evidence from the National Assessment of Educational Progress (NAEP). American Psychologist. Vol. 74, No. 4, 445-458.

[19] Vallerand, R. J. (1997). Toward a Hierarchical Model of Intrinsic and Extrinsic Motivation. In M. P. Zanna (Ed.), Advances in Experimental Social Psychology (Vol. 29, pp. 271-360). New York: Academic Press.

[20] Wu, X. (2003). Intrinsic Motivation and Young Language Learners: The Impact of the Classroom Environment. System. 31 (4) 501-17.

[21] Yuan-bing, D. (2011). How to Motivate Students in Second Language Writing. Sino-US English Teaching, 8(4), 235240. Retrieved from www.davidpublishing.com

[22] Zimmerman, B. J. (2000) Self-Efficacy: An Essential Motive to Learn. Contemporary Educational Psychology. 25 (1), 8291 